\title{
ANÁLISE ESTRUTURAL E FUNCIONAL VOLTADA À PARTICIPAÇÃO QUANTO À REFORMA DA EDUCAÇÃO PELA NOVA LEI DO ENSINO MÉDIO
}

\author{
Rogério Luiz Nery da Silva* \\ Cleber José Tizziani Schneider**
}

\section{Resumo:}

O tema deste estudo é justiça social, com recorte central na inclusão de pessoas negligenciadas por meio da educação voltada ao pleno desenvolvimento como política pública. O problema de pesquisa é discutir o excessivo direcionamento para a educação profissionalizante como inibidor de potencialidades participativas do estudante. Justificativa: atualidade do debate pelo advento da reforma pela nova lei do Ensino Médio. O método de trabalho será dedutivo dialético, com pesquisa qualitativa bibliográfica e normativa. Conclusão: reforma do Ensino Médio põe em risco a autodeterminação dos estudantes ao restringir suas possibilidades de escolha sobre seus destinos.

Palavras-chave: justiça social; educação; reforma; ensino médio; políticas públicas.

\section{STRUCTURAL AND FUNCTIONAL ANALYSIS RELATED TO PARTICIPATION IN THE EDUCATION REFORM BY THE NEWEST BRAZILIAN HIGH SCHOOL LAW}

\begin{abstract}
:
The issue of this study is social justice, with a central sight at the inclusion of neglected people through education focused on full development as a public policy. The research problem is to discuss the excessive orientation towards professional education as an inhibitor of the partipative student's potentialities. Justification: the current debate due to the advent of reform by the new law of High School. The method of work will be dialectical deductive, with qualitative bibliographical and normative research. Conclusion: High School reform puts students' self-determination at risk by restricting their choice of destinations.
\end{abstract}

Key words: social equalty; education; reform; high school; public policies.

\section{Introdução}

Este trabalho busca investigar e discutir a reforma operada pela nova lei do ensino médio brasileiro com vistas a discutir a formação educacional das pessoas, na etapa inicial da vida, que deve ser oferecida de forma a garantir o seu desenvolvimento de forma plena, para além da observância da dignidade humana. O conteúdo a ser disponibilizado ao "aprendente"

*Pós-Doutor em Direitos Fundamentais e Ciência Política (Université de Paris X); Professor do MestradoUniversidade do Oeste de Santa Catarina (UNOESC); Escola da Magistratura do Estado do Rio de Janeiro (EMERJ); Membro Imortal (Cátedra 196) da Academia Brasileira de Ciências Econômicas, Políticas e Sociais (original ANE - fundada em 1944). Email: dr.rogerionery@gmail.com.

**Mestrando em Direito na Universidade do Oeste de Santa Catarina (UNOESC), Analista Judiciário no Tribunal de Justiça de Santa Catarina (TJSC). Email: cjtschneider@gmail.com. 
na chamada "Base Nacional Comum Curricular (BNCC) do Ensino Médio" é tema da maior relevância.

O direcionamento demasiado da base conteudística, voltado a atingir um determinado fim, não amplamente engrandecedor do ser humano será o problema de pesquisa a ser enfrentado, à luz dos princípios que orientam a educação e as políticas públicas educacionais. A partir de distintas visões sobre o que vem a ser a formação completa do indivíduo, o estudo busca identificar resultados díspares quanto à adequação da nova legislação, principalmente se considerada a ênfase dada pelo "novo ensino médio" à "qualificação para o trabalho", em nível técnico intermediário.

Busca-se ofertar uma crítica às escolhas feitas pela nova regra legislativa que podem sacrificar a noção de "educação justa e de qualidade", a partir de algumas posições filosóficas clássicas ou contemporâneas. Cuida-se de pesquisa bibliográfica, cujo método de trabalho adotado é o dedutivo, de modo a partir das ideias gerais apresentadas, apresentar possíveis soluções ao problema proposto.

\section{Inclusão como forma de Justiça social}

O tema é afeto aos direitos sociais, construções jurídicas objeto de reconhecimento como de segunda dimensão, asseguram tutelas de índole protetivas e/ou prestacionais positivas pelo Estado, como forma de viabilizar a igualdade material, é de interesse geral. A investigação de possíveis formas de realização da Justiça Social é permeada pela construção de políticas públicas educacionais inclusivas que atendam aos critérios elencados na Constituição, com o fim de definir sua forma, conteúdo e alcance sob a forma de decisões condizentes com razão pública.

Na Revolução Francesa, a ideia de justiça era profana, sendo resultado de um processo originado no humanismo da Renascença. A ideia de justiça passa a ser a igualdade dos seres humanos, livres por natureza e criadores de seu próprio destino político e de sua ordem jurídica, colocando-se, ainda, ao lado da igualdade e da liberdade, a fraternidade. Kant, todavia, não posiciona a fraternidade em destaque, em seu conceito de justiça, como o faz com a liberdade (elemento ético) e com a igualdade. Apresenta a liberdade como inerente ao ser humano, primeiro bem que se deve reconhecer a cada indivíduo, para, em seguida, somar o valor igualdade. Assentam-se, assim as bases para um projeto de "paz perpétua", tanto interna quanto internacional. Essa ideia de justiça em Kant não é a que se entende por justiça social. 
Justiça social, para Salgado (2012, p. 4), “(...) é a ideia norteadora da consciência política dos povos civilizados contemporâneos, nascida sob as condições históricas mais complexas". Assim, a ideia de justiça que informa o Estado de direito, como Estado de direito, simplesmente, é a realização da liberdade na visão kantiana. Diversamente, o autor considera que a ideia de justiça contemporânea não se restringe ao conteúdo apenas ético da liberdade ou da paz perpétua, mas, estende-se às questões que envolvem as condições concretas de vida do povo e dá relevância ao aspecto social. Busca não só a paz, mas, também, a felicidade perpétua. A justiça social é um dever-ser a nortear a ação política contemporânea.

Ao posicionar a liberdade em primeiro plano, acima da igualdade, converge para o interesse da classe burguesa, em ascensão, quanto à ideia de livre troca de bens, inspirada no ideário de Adam Smith, na força de trabalho, segundo uma concepção individualista de liberdade. Portanto, para Salgado, não é suficiente para descreditar a ideia kantiana de liberdade, compreendida como a liberdade de todos os homens. A liberdade, embora revelada nas condições materiais de vida, de uma determinada classe - a burguesia, a seu ver (2012, p. 212), “(...) não é de interesse dessa classe somente, mas de todo ser racional, ou de todos os homens, individual e coletivamente considerados, porque o interesse da razão (...) é a própria liberdade".

O direito à educação precisa ser faceado sob um novo olhar, que supere a velha utilização como mero instrumento de dominação, controlado por estruturas do poder. O poder político deve atuar objetivamente, sob o risco de se perverter na busca de realizar o controle social. A educação tem origem mais íntima no amor entre as pessoas, de pais para filhos, como forma de proteger das ameaças e preparar para a vida, não advém de uma estrutura de poder, pura e simplesmente, voltada à dominação do indivíduo. ${ }^{1}$

O direito à educação é um paradigma novo. Tradicionalmente, a educação pode ser vista como um paradigma de subdesenvolvimento ético, psicológico e político. Contudo, o novo direito à educação tem uma significação revolucionária que indica a independência das amarras do poder de dominação dos atores estatais que o controla. ${ }^{2}$ Assim, a razão pedagógica deve se

\footnotetext{
1 "No se puede relegar la educacion a la estrutura de poder. El poder sólo puede actuar subsidiariamente respecto a la educación. La comprensión de lo que el hombre es y cómo puede ser educado solo puede partir de la experiência íntima en la vida familiar. Toda objetividad que se arroga el poder político a la hora de educar, degenera fácilmente en una educación para el control social. La educacions tiene su origem en el amor interpersonal que sólo puede darse entre personas, padres y hijos, y no en el interés de la estrutura de poder para con el indivíduo" (BARRAYCOA, 2002, pp. 120-121).

2 "A educação já não está centrada na terra dos adultos, nem no sol da infância, mas projetada no universo dos direitos do ser humano, onde não há maiores e menores, pais e filhos, professores e alunos, mas sujeitos iguais em dignidade e direitos" (MONTEIRO, 2003, p. 787).
} 
afastar razão biológica da família ou da razão política do Estado, devendo ser considerada a razão ética do Educando, limitadora da omnipotência do Estado que dita o arbítrio parental, na tentativa de perpetuar as estruturas sociais.

Salgado (2012, p. 215-217) considera que Kant não poderia pensar que a força de trabalho pudesse ser considerada uma mercadoria, da qual o empregado pudesse dispor com certa liberdade, tendo sido levado a admitir a chamada contingência empírica na teoria do cidadão, como necessária para expurgar o teor empírico de uma atividade, a representar a realização da eticidade no campo político: a "co-legislação", a qual não deve ser violada.

A propriedade é posta como instrumento de independência para o exercício da liberdade, o que autoriza interpreta-lo como seguidor da teoria do poder da sociedade civil dominante na Europa desde Aristóteles, que a estudou pelos dados empíricos da sociedade grega. Prossegue assentando: “(...) a dignidade do pensador legitima concebermos a ideia da autossuficiência como uma exigência a priori do funcionamento da sociedade civil, segundo princípio da razão pura prática".

Apesar de admitir que a propriedade rentável seja uma das condições de autossuficiência, garantindo, assim, a livre legislação, de forma racional, sem intervenção do Estado, há em Kant algo de novo em relação aos demais filósofos desde Aristóteles, qual seja: a base de sua teoria é, nas palavras de Salgado, “(...) o princípio da liberdade de todos os homens e, por conseguinte, sua igualdade originária”.

Da liberdade negativa, todos os membros da sociedade deveriam participar, dentro de uma ordem jurídica. Já da liberdade positiva, entendida como autonomia política, na prática, nem todos participavam, visto que era necessário satisfazer determinadas condições para tanto, dentre elas a propriedade de bens. Isso vai ao encontro da concepção qualitativa de cidadão de Aristóteles. Não obstante, o mérito de Kant está em que a abstração possibilita considerar que, abstratamente, todos os cidadãos poderão vir a ser considerados como iguais, considerada a igualdade abstrata.

Da concepção de cidadão em Kant, pautada, também, na igualdade, ainda que abstratamente considerada, é que se planta a semente da igualdade material. A dignidade, entendida como dever de respeitar o "outro" (alteridade) como um fim, em si mesmo, e não, como coisa, associada à chamada liberdade positiva (política), são capazes de sustentar a concepção de justiça social contemporânea. Não se pode, contudo, considerar que somente alguns têm liberdade, como se supõe que Kant fizesse, devendo-se possibilitar a inclusão de todas as pessoas, independentemente das suas posses. 
Conclui-se, parcialmente, que as múltiplas visões de educação, mesmo partindo de diversas matrizes teóricas da mais diversa inspiração ideológica, mesmo assim tendem a convergir sobre a maioria dos pontos de análise e parâmetros de aferição.

\section{Educação e o direito ao pleno desenvolvimento das capacidades individuais como corolário do princípio da igualdade}

A necessidade de formação completa do indivíduo em fase de desenvolvimento é uma forma de assegurar-lhe dignidade. Para além dessa compreensão estrita de "desenvolvimento" restrito à "fase de crescimento" biológico, a educação passa a ser projetada internacionalmente como o interesse sobre o desenvolvimento pessoal do indivíduo, no sentido de oferecer-lhe as possibilidades de realização máximas como pessoa, de atingir o desenvolvimento como ser e como profissional. Por essa razão, mostra-se relevante a discussão quanto à conveniência ou não de um possível direcionamento da prática escolar que parece ter sido a adotada para reger o novo Ensino Médio, que se anuncia voltado a escolhas de áreas de profissionalização, o que permite, de certa forma, questionar se tal decisão não corresponderá, de outra sorte, a uma escolha precoce, que fechará a porta para outras áreas. Quando se tratar de escolhas profissionalizantes, o funil pode se tornar ainda mais restritivo, a representar simples qualificação de mão-de-obra para o mercado de trabalho, por vezes comprometido com interesses regionais ou locais de certos empregadores da área.

Como forma de responder à questão proposta, faz-se necessário categorizar a educação com auxílio de alguns aportes filosóficos a fim de poder contrastar a hipótese de falha da lei, traduzida na pretensão de institucionalizar a formação profissional como forma principal de educação básica, a ser trabalhada nos currículos escolares, construídos com base na Base Nacional Comum Curricular (BNCC) e seus temas transversais.

Muliari (2013) afirma que a educação, na visão kantiana, era responsável por auxiliar na formação moral do indivíduo, formação esta fundamentada principalmente na possibilidade de aquisição da autonomia por parte do sujeito. Com isso, quer-se responder à questão que se coloca, qual seja, apresentar os motivos pelos quais se educa.

A liberdade kantiana prevê um momento de individualização, que destaca o homem do grupo. Paradoxalmente, constata Salgado (2012, p. 200) que a liberdade somente pode ser desenvolvida em sociedade, pela educação, afirmando: “(...) só é possível na sociedade, uma 
vez que é formação recebida de outro". O direito, por sua vez, é a forma que se tem para se alcançar a liberdade, pois desempenha uma função educadora para a liberdade.

Já em Rawls, na terceira parte da obra Teoria da Justiça (1997), desenvolve-se a concepção de educação e formação moral. Trata-se do desenvolvimento do senso de justiça, que norteia a educação. A partir do arranjo das bases sobre as quais se firma a justiça e dos fins a que pretende chegar sua concepção de justiça como equidade, pondera sobre as suas concepções sobre bens individuais. A educação para a justiça é compatível com os princípios que as partes escolheriam com racionalidade deliberativa num situação inicial de igualdade, sob o véu da ignorância, numa sociedade democrática.

O papel da educação, em Rawls, está diretamente ligado aos conceitos de "sociedade bem ordenada" e "bens primários", sendo entendida a educação como meio pelo qual se desenvolvem habilidades e aptidões individuais. A sociedade bem ordenada é aquela regulada por uma concepção pública de justiça, sabida e aceita por todos os seus integrantes. Os bens sociais primários, segundo a visão do autor, devem ser oportunizados a todos, sendo que, há prevalência de determinados bens sobre outros, como, por exemplo, a importância destinada pelo autor ao bem primário "autoestima". A educação visa, então, cultivar os bens primários necessários à deliberação política e moral, preservando, assim o caráter deliberativo das razões (ROHLING, 2012).

Nussbaum (2013, p. 390) defende que os governos nacionais devem focar, em matéria de educação, na extensão de oportunidades básicas para todos. Isso implica preocupação com as capacidades ou habilidades e com os desfavorecidos e excluídos, sugerindo, preferência no financiamento de grupos que forneçam educação para mulheres e outras minorias (senão maiorias), para superação das negligências.

Conforme esse posicionamento, também as nações prósperas têm a responsabilidade de fornecer uma parte substancial de seus PIB às nações pais pobres. A autora afirma que embora o valor percentual possa ser discutível, o enunciado do princípio geral não o é. Portanto, sugere um mínimo de $2 \%$ (dois por cento) o Produto Interno Bruto das nações prósperas seria um número inicial moralmente adequado. Todavia, constata que os Estados Unidos da América consagrou $0,01 \%$ do PIB para a ajuda externa; já as nações europeias consagraram um pouco menos de $1 \%$ (um por cento).

Não obstante, afirma Nussbaum (2013, p. 390) que a corrupção governamental ou a prática de formas injustas de lidar com as minorias desfavorecidas autorizaria as nações ricas a se utilizar de organizações não-governamentais (ONG’s) para repasse dos recursos. Cita o 
exemplo do financiamento da educação na Índia em 2003, que poderia ter sido feito por intermédio de ONG's em vez do governo nacional, caso algum ministro da educação estivesse empenhado, por exemplo, em hinduizar o currículo, em vez de focar na extensão de oportunidades básicas para todos.

Reafirma a autora a crítica a Rawls, no sentido de que os princípios por ela defendidos dão ênfase às capacidades das pessoas, à igualdade, à possibilidade de mobilidade dentro da própria nação, à satisfação da vida etc. O enfoque de Nussbaum (2013, p. 397) é o "respeito igual pelas pessoas”, o que é demonstrado, nas suas palavras, “(...) pelos compromissos em promover as capacidades humanas para toda e qualquer pessoa e em remover as características estruturais do sistema mundial (...)". Tais características estruturais colocam-se entre as pessoas e as oportunidades de vida decentes, sendo que, deve-se respeitar o compromisso, nas palavras da autora, “(...) em promover toda e qualquer capacidade, em vez de tratar alguns assuntos humanos importantes como meramente instrumentais para a busca da riqueza”.

A partir dessas múltiplas visões de igualdade e do papel da educação, pode-se encaminhar certas críticas à já apelidada de "Nova Lei do Ensino Médio".

\section{Análise estrutural e funcional da nova lei do Ensino Médio}

A Base Nacional Comum Curricular $(\mathrm{BNCC})^{3}$ é um documento de caráter normativo que define o conjunto orgânico e progressivo de aprendizagens essenciais que todos os alunos devem desenvolver ao longo das etapas e modalidades da Educação Básica.

\footnotetext{
${ }^{3}$ Segue um breve histórico de sua formação, apresentada no sítio www.basenacionalcomum.mec.gov.br, acesso em 19/06/2017: "1988 - É promulgada em nossa Constituição Federal. A criação de uma Base Nacional Comum Curricular, com a fixação de conteúdos mínimos para o ensino fundamental, é prevista no artigo 210. 1996 - A LDB da Educação Básica é aprovada e reforça a necessidade de uma base nacional comum. 1997 até 2000 - A partir das diretrizes curriculares (DCNS) e dos Parâmetros Curriculares Nacionais (PNCs) foram apresentados aos educadores, colocando em destaque alguns aspectos fundamentais de cada disciplina. $\mathbf{2 0 1 0}$ - Conferência Nacional da Educação (CONAE), no ano de 2010 especialistas discutiram a Educação Básica e salientaram a necessidade da BNC como parte do Plano Nacional da Educação. 2010 a 2012 - Novas diretrizes curriculares nacionais, orientadas para o planejamento curricular das escolas e sistemas de ensino, as resoluções valiam para a educação infantil e os ensinos fundamental e médio. 2014 - Plano Nacional de Educação (PNE), a lei 13.005, de 2014 institui o PNE com vigência de 10 anos. São 20 metas para melhorar a qualidade da Educação Básica sendo que quatro delas tratam da Base Nacional Comum Curricular. 2015 - Elaboração da Base Nacional Comum Curricular (BNCC), em 2015 ocorre $1^{\circ}$ Seminário Interinstitucional para a elaboração da base. A portaria 592, instituiu uma comissão de especialistas para a elaboração de proposta BNCC. 2016 - Base no papel - em março de 2016, a $1^{\text {a }}$ versão do documento. Em junho seminários com professores, gestores e especialistas para a discussão da $2^{\mathrm{a}}$ versão. Em agosto a $3^{\mathrm{a}}$ versão. 2017 - Nas mãos do conselho - em abril de 2017 o MEC entrega a versão final da Base Nacional Comum Curricular (BNCC), ao Conselho Nacional da Educação (CNE), a partir da homologação da BNCC, começa o processo de formação de professores e o apoio ao sistema de educação estaduais e municipais para adequação dos currículos escolares."
} 
Salienta-se a importância de uma base nacional comum curricular para o Brasil, com o foco na aprendizagem, como estratégia para fomentar a qualidade da educação básica em todas as etapas e modalidades. Repisando, o que se insere na base comum é o problema que deve ser enfrentado à luz dos princípios que orientam as políticas públicas educacionais. Aí, confrontam-se diferentes doutrinas que apoiam, de um lado, a formação completa do indivíduo e, de outro, a qualificação da força de trabalho.

As conclusões prévias a respeito da Lei n. 13.415, de 16 de fevereiro 2017 (nova lei do Ensino Médio) revelaram as dificuldades em se estabelecer uma política pública educacional, especialmente, a ligada ao Ensino Médio. Nesse prisma, objetiva-se discutir a construção de políticas públicas educacionais inclusivas, que passem pelos critérios do razoável, diante do atual contexto social e econômico, estudando-se os motivos justificadores de uma alteração que se anuncia como profunda no sistema educacional.

Vale destacar que a proposta de Ensino Médio com carga horária ampliada já estava presente, antes do advento da chamada nova Lei do Ensino Médio, no chamado Ensino Médio Inovador $(E M I)^{4}$. Por esse programa, que visa desenvolver e reestruturar o "ensino não profissionalizante", mediante inovação curricular, além dos componentes curriculares comuns, do período regular, os estudantes frequentam a escola a fim de exercer atividades, “(...) de forma a combinar formação geral, científica, tecnológica, cultural e conhecimentos técnicoexperimentais" (artigo $2^{\circ}$, parágrafo único, inciso II).

$\mathrm{O}$ art. $2^{\circ}$ da Lei 13.415/2017 altera o art. $26^{5}$ da Lei n. 9.394, de 20 de dezembro de 1996, que passa a vigorar com diversas alterações estruturais, especialmente as referentes à "arte e suas expressões regionais"; "inclusão de temas transversais" e a restrição de inclusão de novos componentes curriculares, sem a aprovação do Conselho Nacional de Educação (CNE). O $\S 2^{\circ}$ do art. 26 da Lei n. 9.394/1996 foi alterado pela Lei n. 13.415/2017, mas não inovou em

\footnotetext{
${ }^{4}$ O programa Ensino Médio Inovador (EMI) foi instituído pela Portaria n. 971, de 9 de outubro de 2009, no contexto da implementação das ações voltadas ao Plano de Desenvolvimento da Educação - PDE.

5 “Art. 26. (...) $\S 2^{\circ} \mathrm{O}$ ensino da arte, especialmente em suas expressões regionais, constituirá componente curricular obrigatório da educação básica. (...) $\S 5^{\circ}$ No currículo do ensino fundamental, a partir do sexto ano, será ofertada a língua inglesa. (...) $\S 7^{\circ} \mathrm{A}$ integralização curricular poderá incluir, a critério dos sistemas de ensino, projetos e pesquisas envolvendo os temas transversais de que trata o caput. (...) § 10 . A inclusão de novos componentes curriculares de caráter obrigatório na Base Nacional Comum Curricular dependerá de aprovação do Conselho Nacional de Educação e de homologação pelo Ministro de Estado da Educação." No art. 26, caput, da Lei n. 9.394/1996, na redação conferida pela Lei n. 12.796/2013, consta que o currículo de ensino médio deve ter uma "(...) base nacional comum, a ser complementada, em cada sistema de ensino e em cada estabelecimento escolar, por uma parte diversificada, exigida pelas características regionais e locais da sociedade, da cultura, da economia e dos educandos".
} 
relação ao dispositivo revogado, mantendo o ensino da arte, “especialmente em suas expressões regionais, como componente curricular obrigatório da educação básica”.

Todavia, o conceito de componente curricular obrigatório é impreciso na Lei. Em relação à Língua Portuguesa e Matemática, consta no $§ 1^{\text {o6 }}$ do art. 26 da Lei n. 9.394/1996 que é obrigatório "o estudo da língua portuguesa e da matemática, o conhecimento do mundo físico e natural e da realidade social e política, especialmente do Brasil". Não há referência expressa às disciplinas referidas no referido $\S 1^{\circ}$ como sendo "componente curricular obrigatório".

Houve uma tentativa de retirar a obrigatoriedade do ensino de Artes $^{7}$ e da Educação Física $^{8}$ no Ensino Médio, via medida provisória. Com a conversão em lei, mantiveram-se os dispositivos, suprimindo-se, contudo, em relação a Artes a expressão "de forma a promover o desenvolvimento cultural dos alunos". Estabeleceram-se as matérias que, tradicionalmente, constam como componentes da matriz curricular, como a Língua Portuguesa, Matemática, História $^{9}$, Geografia, Biologia, Física, Química, Sociologia, Filosofia, Artes, Educação Física e Língua Estrangeira.

Quanto à Língua Estrangeira, a Lei n. 13.415/2107 inovou ao tornar obrigatório o ensino da Língua Inglesa ao Ensino Fundamental a partir do quinto ano do Ensino

\footnotetext{
6 “§ $1^{\circ}$ Os currículos a que se refere o caput devem abranger, obrigatoriamente, o estudo da língua portuguesa e da matemática, o conhecimento do mundo físico e natural e da realidade social e política, especialmente do Brasil." ${ }^{7}$ Eis a redação original da Lei n. 9.394/1996: "§ $2^{\circ} \mathrm{O}$ ensino da arte constituirá componente curricular obrigatório, nos diversos níveis da educação básica, de forma a promover o desenvolvimento cultural dos alunos". Em 2010, a Lei n. 12.287 promoveu sensível alteração, ao estabelecer que o ensino da Arte de observar as expressões regionais (" $\$ 2^{\circ} \mathrm{O}$ ensino da arte, especialmente em suas expressões regionais, constituirá componente curricular obrigatório nos diversos níveis da educação básica, de forma a promover o desenvolvimento cultural dos alunos.”). Via Medida Provisória n. 746, de 2016, tentou-se suprimir a obrigatoriedade do ensino da Arte ao Ensino Médio (“\$ $2^{\circ} \mathrm{O}$ ensino da arte, especialmente em suas expressões regionais, constituirá componente curricular obrigatório da educação infantil e do ensino fundamental, de forma a promover o desenvolvimento cultural dos alunos."). $\mathrm{O}$ ensino da arte é reforçado pelo $\S 6^{\circ}$ do art. 26 da Lei n. 9.394/1996, na redação dada pela Lei no 13.278 , de 2016: " $\$ 6^{\circ}$ As artes visuais, a dança, a música e o teatro são as linguagens que constituirão o componente curricular de que trata o $\S 2^{\circ}$ deste artigo". Bem como, o $\S 8^{\circ}$ do art. 26 estabelece: "§ $8^{\circ}$ A exibição de filmes de produção nacional constituirá componente curricular complementar integrado à proposta pedagógica da escola, sendo a sua exibição obrigatória por, no mínimo, 2 (duas) horas mensais" (Incluído pela Lei no 13.006, de 2014).

8 "§ $3^{\circ} \mathrm{A}$ educação física, integrada à proposta pedagógica da escola, é componente curricular obrigatório da educação básica, sendo sua prática facultativa ao aluno: (Redação dada pela Lei n. 10.793, de $1^{\circ} .12 .2003$ ) I - que cumpra jornada de trabalho igual ou superior a seis horas; (Incluído pela Lei n. 10.793, de $1^{\circ}$.12.2003) II - maior de trinta anos de idade; (Incluído pela Lei n. 10.793, de $1^{\circ} .12 .2003$ ) III - que estiver prestando serviço militar inicial ou que, em situação similar, estiver obrigado à prática da educação física; (Incluído pela Lei n. 10.793, de $1^{\circ}$.12.2003) IV - amparado pelo Decreto-Lei no 1.044, de 21 de outubro de 1969; (Incluído pela Lei n. 10.793, de $\left.1^{\circ} .12 .2003\right) \mathrm{V}$ - (VETADO) (Incluído pela Lei n. 10.793, de $\left.1^{\circ} .12 .2003\right) \mathrm{VI}$ - que tenha prole." (Incluído pela Lei n. 10.793, de $\left.1^{\circ} .12 .2003\right)$

${ }^{9}$ Quanto ao ensino de História, há dispositivo específico, qual seja o $\S 4^{\circ}$ do art. 26 da Lei n. 9.394/1996 ("O ensino da História do Brasil levará em conta as contribuições das diferentes culturas e etnias para a formação do povo brasileiro, especialmente das matrizes indígena, africana e européia.").
} 
Fundamental ${ }^{10}$. Trata-se de uma imposição de uma língua estrangeira, a qual, antes, podia ser livremente escolhida pela "comunidade escolar, dentro das possibilidades da instituição".

O $§ 10$ do art. 26 da Lei n. 9.394/1996, incluído pela Lei $n^{\circ}$ 13.415, de 2017, excluiu o Conselho Nacional de Secretários de Educação (Consed) e a União Nacional de Dirigentes de Educação (Undime), entidades incluídas pela MP n. 746/2016, do processo de inclusão na Base Nacional Comum Curricular de novos componentes curriculares de caráter obrigatório, atribuindo tal competência, exclusivamente, ao Conselho Nacional de Educação, mediante homologação do Ministro de Estado da Educação.

Apesar disso, o $§ 7$ ํㅡo do art. 26 da Lei n. 9.394/1996, na redação dada pela Lei n. 13.415, de 2017, estabelece que “(a) integralização curricular poderá incluir, a critério dos sistemas de ensino, projetos e pesquisas envolvendo os temas transversais de que trata o caput". Mantevese a atribuição exclusiva dos sistemas de ensino para incluir projetos e pesquisas envolvendo os temas transversais. O caput do art. 26 estabelece que a Base Nacional Comum será "complementada, em cada sistema de ensino e em cada estabelecimento escolar, por uma parte diversificada, exigida pelas características regionais e locais da sociedade, da cultura, da economia e dos educandos”. Não obstante, tentou-se com a MP n. 746/2016 restringir à Base Nacional Comum Curricular, também, a implementação de temas transversais nos currículos do ensino ${ }^{11}$.

\footnotetext{
${ }^{10}$ Consta da redação original da Lei n. 9.394/1996: "§ $5^{\circ}$ Na parte diversificada do currículo será incluído, obrigatoriamente, a partir da quinta série, o ensino de pelo menos uma língua estrangeira moderna, cuja escolha ficará a cargo da comunidade escolar, dentro das possibilidades da instituição". Medida Provisória nº 746, de 2016 trouxe a redação que após foi sensivelmente alterada pela Lei n. 13416/2017, que optou por tornar obrigatório o ensino da Língua Inglesa a partir do quinto ano do Ensino Fundamental. Eis a redação dada pela MP n. 746/2016: "§ $5^{\circ}$ No currículo do ensino fundamental, será ofertada a língua inglesa a partir do sexto ano".

${ }^{11}$ Assim dispunha a redação do $\S 7^{\circ}$, nos termos da Lei no 12.608 , de 2012: "Os currículos do ensino fundamental e médio devem incluir os princípios da proteção e defesa civil e a educação ambiental de forma integrada aos conteúdos obrigatórios". Tal dispositivo foi alterado, primeiramente, pela (Redação dada pela Medida Provisória $\mathrm{n}^{\circ}$ 746, de 2016, que assim dispôs: "§ $7^{\circ}$ A Base Nacional Comum Curricular disporá sobre os temas transversais que poderão ser incluídos nos currículos de que trata o caput." Na redação da MP 746/2016, aparentemente, visavase estabelecer norma geral, em consonância com o caput do art. 26, na parte em que estabelece que a Base Nacional Comum será "complementada, em cada sistema de ensino e em cada estabelecimento escolar, por uma parte diversificada, exigida pelas características regionais e locais da sociedade, da cultura, da economia e dos educandos". Todavia, o $\S 7^{\circ}$ do art. 26 sofreu modificação em seu conteúdo pela Lei n. 13.415/2017, a qual manteve a atribuição exclusiva dos sistemas de ensino para incluir projetos e pesquisas envolvendo os temas transversais. Um exemplo de tema transversal, estabelecido na própria LDB (Lei n. 9.394/1996) está previsto no $\S 9^{\circ}$ do art. 26, incluído pela Lei n. 13.010, de 2014, o qual estabelece: "§ $9^{\circ}$ Conteúdos relativos aos direitos humanos e à prevenção de todas as formas de violência contra a criança e o adolescente serão incluídos, como temas transversais, nos currículos escolares de que trata o caput deste artigo, tendo como diretriz a Lei no 8.069, de 13 de julho de 1990 (Estatuto da Criança e do Adolescente), observada a produção e distribuição de material didático adequado."
} 
Não obstante, em relação aos componentes obrigatórios, fortaleceu-se o papel da Base Nacional Comum Curricular. O art. $35^{12}$ da Lei n. 9.394/1996 estabelece que o ensino médio é “etapa final da educação básica, com duração mínima de três anos”. Em seus incisos, I a IV, estão escritas as finalidades do ensino médio. A este artigo foi acrescido o Art. $35-\mathrm{A}^{13}$, cujo caput e incisos dispõem que "(a) Base Nacional Comum Curricular definirá direitos e objetivos de aprendizagem do ensino médio, conforme diretrizes do Conselho Nacional de Educação, nas seguintes áreas do conhecimento: I - linguagens e suas tecnologias; II - matemática e suas tecnologias; III - ciências da natureza e suas tecnologias; IV - ciências humanas e sociais aplicadas".

Logo, o que o legislador estabeleceu quando dispôs que a "Base Nacional Comum Curricular definirá direitos e objetivos de aprendizagem do ensino médio" e definiu as áreas de conhecimento que serão objeto da BNCC, foi a atribuição de maior força jurídica à Base Nacional de Ensino (BNCC). Nessa medida, ampliou-se a perda de autonomia das escolas na organização de seus currículos e do trabalho pedagógico no que se refere à formação da grade curricular. Ao centralizar a definição dos direitos e objetivos de aprendizagem do Ensino Médio

\footnotetext{
12 “Art. 35. O ensino médio, etapa final da educação básica, com duração mínima de três anos, terá como finalidades: I - a consolidação e o aprofundamento dos conhecimentos adquiridos no ensino fundamental, possibilitando o prosseguimento de estudos; II - a preparação básica para o trabalho e a cidadania do educando, para continuar aprendendo, de modo a ser capaz de se adaptar com flexibilidade a novas condições de ocupação ou aperfeiçoamento posteriores; III - o aprimoramento do educando como pessoa humana, incluindo a formação ética e o desenvolvimento da autonomia intelectual e do pensamento crítico; IV - a compreensão dos fundamentos científico-tecnológicos dos processos produtivos, relacionando a teoria com a prática, no ensino de cada disciplina."

13 "Art. 35-A. A Base Nacional Comum Curricular definirá direitos e objetivos de aprendizagem do ensino médio, conforme diretrizes do Conselho Nacional de Educação, nas seguintes áreas do conhecimento: I - linguagens e suas tecnologias; II - matemática e suas tecnologias; III - ciências da natureza e suas tecnologias; IV - ciências humanas e sociais aplicadas. $\S 1^{\circ}$ A parte diversificada dos currículos de que trata o caput do art. 26, definida em cada sistema de ensino, deverá estar harmonizada à Base Nacional Comum Curricular e ser articulada a partir do contexto histórico, econômico, social, ambiental e cultural. $\S 2^{\circ}$ A Base Nacional Comum Curricular referente ao ensino médio incluirá obrigatoriamente estudos e práticas de educação física, arte, sociologia e filosofia. $\S 3^{\circ} \mathrm{O}$ ensino da língua portuguesa e da matemática será obrigatório nos três anos do ensino médio, assegurada às comunidades indígenas, também, a utilização das respectivas línguas maternas. $§ 4^{\circ}$ Os currículos do ensino médio incluirão, obrigatoriamente, o estudo da língua inglesa e poderão ofertar outras línguas estrangeiras, em caráter optativo, preferencialmente o espanhol, de acordo com a disponibilidade de oferta, locais e horários definidos pelos sistemas de ensino. § $5^{\circ} \mathrm{A}$ carga horária destinada ao cumprimento da Base Nacional Comum Curricular não poderá ser superior a mil e oitocentas horas do total da carga horária do ensino médio, de acordo com a definição dos sistemas de ensino. § $6^{\circ} \mathrm{A}$ União estabelecerá os padrões de desempenho esperados para o ensino médio, que serão referência nos processos nacionais de avaliação, a partir da Base Nacional Comum Curricular. § $7^{\circ}$ Os currículos do ensino médio deverão considerar a formação integral do aluno, de maneira a adotar um trabalho voltado para a construção de seu projeto de vida e para sua formação nos aspectos físicos, cognitivos e socioemocionais. $\S 8^{\circ}$ Os conteúdos, as metodologias e as formas de avaliação processual e formativa serão organizados nas redes de ensino por meio de atividades teóricas e práticas, provas orais e escritas, seminários, projetos e atividades on-line, de tal forma que ao final do ensino médio o educando demonstre: I - domínio dos princípios científicos e tecnológicos que presidem a produção moderna; II - conhecimento das formas contemporâneas de linguagem."
} 
num único órgão, qual seja, o Conselho Nacional de Educação (CNE), reduz-se o papel da escola e dos sujeitos escolares na construção dos currículos de ensino.

$\mathrm{Na}$ forma disposta nos incisos do art. 35-A da LDB, no interior da base de ensino estabelecida na Base Nacional Comum Curricular serão definidas as seguintes áreas do conhecimento: linguagens e suas tecnologias; matemática e suas tecnologias; ciências da natureza e suas tecnologias; ciências humanas e sociais aplicadas. Pouco espaço de manobra restará para a escola e os sujeitos escolares construírem os currículos de ensino e desenvolverem o trabalho pedagógico de forma autônoma. Essa visão é confirmada pela leitura dos parágrafos do art. 35-A.

Já no $\S 1^{\circ}$ do art. 35-A, firmou-se a sentença segundo a qual a "parte diversificada dos currículos de que trata o caput do art. 26, definida em cada sistema de ensino, deverá estar harmonizada à Base Nacional Comum Curricular e ser articulada a partir do contexto histórico, econômico, social, ambiental e cultural". Afasta-se, assim, com uma certa contradição em relação ao disposto no art. 26, a autonomia dos estabelecimentos escolares. Essa autonomia foi o que se buscou com a não-inclusão da proposta que restringia à BNCC a função de tratar, também, com exclusividade, dos "temas transversais" (ou "parte diversificada") dos currículos do ensino básico, o que é exigido, na forma do caput do art. 26 “(...) pelas características regionais e locais da sociedade, da cultura, da economia e dos educandos".

No $\S 2^{\circ}$ do art. 35-A da LDB consta: “A Base Nacional Comum Curricular referente ao ensino médio incluirá obrigatoriamente estudos e práticas de educação física, arte, sociologia e filosofia". Constata-se que, aqui, o legislador utilizou-se da expressão “incluirá obrigatoriamente estudos e práticas" o que, de fato, não possui a mesma consistência apresentada no texto art. 26, quando trata educação física e arte como "componente curricular". Essa imprecisão pode conduzir a o que já se usa denominar "efeito do Ensino Médio Líquido"14.

\footnotetext{
${ }^{14}$ Mônica Ribeiro (UFPR) argumenta: I) "as únicas disciplinas obrigatórias nos três anos são: Língua Portuguesa e Matemática. É obrigatório ofertar também uma língua estrangeira e, neste caso, também não tem escolha, pois a língua obrigatória é a inglesa; II) Filosofia e Sociologia não constam mais como disciplinas obrigatórias. Seus conteúdos poderão ser ensinados diluídos em outras disciplinas. Excetuando Língua Portuguesa e Matemática, nenhuma outra disciplina é obrigatória, isso significa que todas as demais poderão ser ofertadas também 'diluídas' umas nas outras criando assim o que estou chamando de 'Ensino Médio Líquido'; III) É líquido também porque mergulha no mais profundo abismo a juventude brasileira da escola pública. Porque afunda toda e qualquer possibilidade de uma vida digna para esses/as jovens, conseguida por meio de uma formação escolar densa e crítica, de uma preparação séria para o mundo do trabalho ou para o prosseguimento dos estudos. Sobre esse último, o prosseguimento nos estudos, essa 'liquidez' afoga mais e mais as possibilidades já pequenas de ingresso em uma Universidade pública". Ver notícia completa em: http://www.cedes.unicamp.br/noticias/668, acesso em 09/03/2017.
} 

À REFORMA DA EDUCAÇÃO PELA NOVA LEI DO ENSINO MÉDIO

O chamado "ensino médio líquido" é entendido como uma "flexibilização" que poderá levar a simplificações ou esvaziamentos no trabalho com os conhecimentos científicos presentes nos atuais componentes curriculares, por sua vez, nos propósitos de uma formação humana integral e interdisciplinar, integrado ao eixo trabalho, ciência, tecnologia e cultura, como se vinha defendendo e trabalhando nos últimos anos. Assim, o cenário aponta para a desconstrução Ensino Médio como parte estruturante da Educação Básica.

Nesse passo, no $\S 3^{\circ}$ do art. 35-A da LDB consolida-se a supremacia da língua portuguesa e matemática, cujos conhecimentos constam como obrigatórios nos três anos. Assim, também, o da língua inglesa $\left(\S 4^{\circ}\right)$. Outra língua estrangeira poderá ser ofertada, com preferência ao espanhol, mas em caráter optativo.

O texto do art. $36^{15}$, em seu caput, trata do "currículo do ensino médio", obrigatoriamente, "composto pela Base Nacional Comum Curricular e por itinerários formativos, que deverão ser organizados por meio da oferta de diferentes arranjos curriculares".

\footnotetext{
${ }^{15}$ Art. $4^{\circ}$ da Lei n. 13.415/2017: "O art. 36 da Lei no 9.394, de 20 de dezembro de 1996, passa a vigorar com as seguintes alterações: 'Art. 36 O currículo do ensino médio será composto pela Base Nacional Comum Curricular e por itinerários formativos, que deverão ser organizados por meio da oferta de diferentes arranjos curriculares, conforme a relevância para o contexto local e a possibilidade dos sistemas de ensino, a saber: I - linguagens e suas tecnologias; II - matemática e suas tecnologias; III - ciências da natureza e suas tecnologias; IV - ciências humanas e sociais aplicadas; $\mathrm{V}$ - formação técnica e profissional. § $1^{\circ} \mathrm{A}$ organização das áreas de que trata o caput e das respectivas competências e habilidades será feita de acordo com critérios estabelecidos em cada sistema de ensino. I - (revogado); II - (revogado); (...) § $3^{\circ}$ A critério dos sistemas de ensino, poderá ser composto itinerário formativo integrado, que se traduz na composição de componentes curriculares da Base Nacional Comum Curricular - BNCC e dos itinerários formativos, considerando os incisos I a V do caput. (...) § $5^{\circ}$ Os sistemas de ensino, mediante disponibilidade de vagas na rede, possibilitarão ao aluno concluinte do ensino médio cursar mais um itinerário formativo de que trata o caput. $\S 6^{\circ}$ A critério dos sistemas de ensino, a oferta de formação com ênfase técnica e profissional considerará: I - a inclusão de vivências práticas de trabalho no setor produtivo ou em ambientes de simulação, estabelecendo parcerias e fazendo uso, quando aplicável, de instrumentos estabelecidos pela legislação sobre aprendizagem profissional; II - a possibilidade de concessão de certificados intermediários de qualificação para o trabalho, quando a formação for estruturada e organizada em etapas com terminalidade. § $7^{\circ} \mathrm{A}$ oferta de formações experimentais relacionadas ao inciso $\mathrm{V}$ do caput, em áreas que não constem do Catálogo Nacional dos Cursos Técnicos, dependerá, para sua continuidade, do reconhecimento pelo respectivo Conselho Estadual de Educação, no prazo de três anos, e da inserção no Catálogo Nacional dos Cursos Técnicos, no prazo de cinco anos, contados da data de oferta inicial da formação. $\S 8^{\circ} \mathrm{A}$ oferta de formação técnica e profissional a que se refere o inciso $\mathrm{V}$ do caput, realizada na própria instituição ou em parceria com outras instituições, deverá ser aprovada previamente pelo Conselho Estadual de Educação, homologada pelo Secretário Estadual de Educação e certificada pelos sistemas de ensino. $\S 9^{\circ}$ As instituições de ensino emitirão certificado com validade nacional, que habilitará o concluinte do ensino médio ao prosseguimento dos estudos em nível superior ou em outros cursos ou formações para os quais a conclusão do ensino médio seja etapa obrigatória. § 10. Além das formas de organização previstas no art. 23, o ensino médio poderá ser organizado em módulos e adotar o sistema de créditos com terminalidade específica. § 11. Para efeito de cumprimento das exigências curriculares do ensino médio, os sistemas de ensino poderão reconhecer competências e firmar convênios com instituições de educação a distância com notório reconhecimento, mediante as seguintes formas de comprovação: I - demonstração prática; II experiência de trabalho supervisionado ou outra experiência adquirida fora do ambiente escolar; III - atividades de educação técnica oferecidas em outras instituições de ensino credenciadas; IV - cursos oferecidos por centros ou programas ocupacionais; V - estudos realizados em instituições de ensino nacionais ou estrangeiras; VI - cursos realizados por meio de educação a distância ou educação presencial mediada por tecnologias. § 12. As escolas
} 
No antigo texto deste artigo $^{16}$, abria-se margem para a atuação das escolas na formação do currículo. As diretrizes apontavam, por exemplo, para a obrigatoriedade da oferta de uma língua estrangeira a ser escolhida pela comunidade escolar, podendo ser ofertada uma segunda, em caráter optativo. Nesse passo, as escolas já vinham trabalhando, também, pela oferta do ensino de língua espanhola, alemã, italiana, entre outras. De acordo com o novo texto do art. 36, serão consideradas, para a construção dos chamados itinerários formativos, "a relevância para o contexto local e a possibilidade dos sistemas de ensino".

Nesse ponto, constata-se que, além dos componentes da Base Nacional Curricular Comum (linguagens e suas tecnologias; matemática e suas tecnologias; ciências da natureza e suas tecnologias; ciências humanas e sociais aplicadas), introduziu-se a "formação técnica e profissional" no Ensino Médio a título de "itinerários formativos". O texto proposto para o art. 36 da LDB, em relação aos chamados itinerários formativos, encabeça o que vem sendo chamado de "novo Ensino Médio".

De acordo com o $\S 1^{\circ}$ do art. 36 da LDB, a organização das áreas de que trata o caput e das respectivas competências e habilidades será feita de acordo com critérios estabelecidos em cada sistema de ensino. $\mathrm{O} \S 3^{\circ}$ também delibera que "a critério do sistema de ensino, poderá ser composto itinerário formativo integrado, que se traduz na composição de componentes curriculares da Base Nacional Comum Curricular e dos itinerários formativos". Assim, os sistemas de ensino (e não os jovens estudantes do ensino médio) é que irão decidir sobre como irão ofertar as áreas e os itinerários.

Cabe considerar, neste cenário, que a parte correspondente aos componentes da Base Nacional Comum Curricular não poderá ser superior 1.800 horas nos três anos de Ensino Médio (art. 35-A, $\S 5^{\circ}$, da LDB). Hoje essa carga horária é de 2.400 horas, para aquelas escolas que não adotaram o Ensino Médio em tempo integral.

Vale lembrar que os sistemas de ensino deverão ampliar essa carga horária para 1.000 horas ano, em cinco anos, totalizando 3.000 horas para todo o Ensino Médio. Para o caso das

\footnotetext{
deverão orientar os alunos no processo de escolha das áreas de conhecimento ou de atuação profissional previstas no caput'."

16 "Art. 36. O currículo do ensino médio observará o disposto na Seção I deste Capítulo e as seguintes diretrizes: I - destacará a educação tecnológica básica, a compreensão do significado da ciência, das letras e das artes; o processo histórico de transformação da sociedade e da cultura; a língua portuguesa como instrumento de comunicação, acesso ao conhecimento e exercício da cidadania; II - adotará metodologias de ensino e de avaliação que estimulem a iniciativa dos estudantes III - será incluída uma língua estrangeira moderna, como disciplina obrigatória, escolhida pela comunidade escolar, e uma segunda, em caráter optativo, dentro das disponibilidades da instituição. IV - serão incluídas a Filosofia e a Sociologia como disciplinas obrigatórias em todas as séries do ensino médio."
} 
escolas de E.M. de tempo integral, essa carga horária será ampliada para 1.400 horas-ano, totalizando 4.200 horas de formação no E.M. No entanto, a carga-horária dedicada à BNCC continuará em 1.800 horas para os três anos de E. M., com maior dedicação a Língua Portuguesa e Matemática.

Pode ser visto como um problema o fato de ser possível pela nova lei o chamado "fatiamento do currículo", a partir dos itinerários formativos. O estudante, ao tomar o rumo em um dos itinerários, passará a não mais ter acesso a conhecimentos da área referente a outro itinerário (ou terá acesso reduzido), na sua trajetória de escolarização.

No parecer da Procuradoria Geral da República, da lavra do Procurador Geral Rodrigo Janot, no âmbito da Ação Direta de Inconstitucionalidade n. 5.599, apontou-se a fragilidade do que vem se chamando de "itinerários formativos". Para o Ministério Público Federal, a criação de itinerários formativos específicos (Linguagens, Matemática, Ciências da Natureza, Ciências Humanas e Formação Técnica e Profissional) sem medidas de correção das desigualdades de origem e prevenção ao risco de reforço delas, a MP 746/2016 contribui para violar o objetivo fundamental da redução das desigualdades regionais, o princípio da igualdade e o direito fundamental à educação. Sustenta a Procuradoria-Geral que a escolha desses itinerários não será livre e será influenciada pelos efeitos da desigualdade de origem (raça, gênero, etnia e estrato de classe, por exemplo) e pelas desigualdades nas opções de itinerários disponíveis nas escolas.

A legislação apresentada visa, claramente, a formação para o mercado de trabalho. Amplia-se a formação técnico-profissional, inclusive, por meio de parcerias ( $\S 8^{\circ}$ do art. 36 da LDB), também, com "instituições de educação a distância” (§ 11 do art. 36 da LDB).

A legislação passou a compreender como profissional da educação "profissionais com notório saber reconhecido pelos respectivos sistemas de ensino, para ministrar conteúdos de áreas afins à sua formação ou experiência profissional, atestados por titulação específica ou prática de ensino em unidades educacionais da rede pública ou privada ou das corporações privadas em que tenham atuado, exclusivamente para atender ao inciso V do caput do art. 36" 17 (itinerário voltado para a formação técnico-profissional). A crítica está no fato de que de que,

\footnotetext{
${ }^{17}$ Art. $6^{\circ}$ da Lei n. 13.415/2017: "O art. 61 da Lei n. 9.394, de 20 de dezembro de 1996, passa a vigorar com as seguintes alterações: 'Art. 61. (...) IV - profissionais com notório saber reconhecido pelos respectivos sistemas de ensino, para ministrar conteúdos de áreas afins à sua formação ou experiência profissional, atestados por titulação específica ou prática de ensino em unidades educacionais da rede pública ou privada ou das corporações privadas em que tenham atuado, exclusivamente para atender ao inciso $\mathrm{V}$ do caput do art. 36; $\mathrm{V}$ - profissionais graduados que tenham feito complementação pedagógica, conforme disposto pelo Conselho Nacional de Educação (...)' (NR)".
} 
além de não se exigir formação para a docência, soa como um aviso do caminho seguido pelo Legislador rumo a contratações sem concurso público.

Por outro lado, o Art. $7^{\circ}$ da lei em discussão altera o disposto no Art. 62 da LDB 9.394/96, que trata da formação docente. Consta que "os currículos dos cursos de formação de docentes terão por referência a BNCC" $\left(\S 8^{\circ}\right)$. Exclui-se a exigência constante na redação anterior que a licenciatura plena ocorresse em cursos oferecidos por "universidades e institutos superiores de educação" Já o Art. 11 delibera que os cursos de licenciatura deverão adequar-se no prazo de dois anos, "contando da publicação da BNCC".

Ficará mais difícil o ingresso no Ensino Superior pelos estudantes das escolas públicas que aderirem ao "novo Ensino Médio", na medida em que tal ingresso tem como referência a Base Nacional Comum Curricular, agora limitada pelo fatiamento dos componentes curriculares. Some-se a isso o fato de os adolescentes buscarão sua independência e tenderão a optar por itinerários profissionalizantes a fim de garantir uma vaga no concorrido e escasso ambiente laboral.

Apesar do discurso quanto à necessidade social da subordinação da escola às demandas produtivas, ainda não foi implementada pelo Ministério da Educação a nova Base Nacional Comum Curricular, fato que, também, demonstra a ausência de urgência necessária para edição de uma Medida Provisória para tratar desse assunto. No art. 12 da Lei n. 13.415/2017 consta um mandamento para os sistemas de ensino estabelecerem cronograma de implementação das alterações na Lei no 9.394, de 20 de dezembro de 1996, e iniciar o processo de implementação, a partir do segundo ano letivo subsequente à data de homologação da Base Nacional Comum Curricular.

A escola, de acordo com a Confederação Nacional da Indústria (2007), deverá adequar-se às novas tecnologias, possibilitando a formação de quadros com novos perfis profissionais, com maior escolaridade, em especial de nível médio, superior e tecnólogos, nas áreas de automação industrial (Computer Aided Design / Computer Aided Manufacturing CAD/CAM; Controlador Lógico Programável - CLP); sistema de manufatura integrada (Computer Integrated Manufactoring - CIM; Sistema Digital de Controle Distribuído - SDCD.

Defende a Confederação Nacional da Indústria que a formação dos jovens seja condizente com as novas tecnologias e, para tanto, seria imprescindível a modernização das escolas, novos conteúdos de formação, educação a distância, aprendizagem flexível, educação empreendedora, educação na empresa. Para Mello (2012), os padrões de gestão defendidos pela CNI têm alinhamento com o chamado "toyotismo", pregando a qualidade total, a segurança no 
trabalho, a economia de tempo e de materiais, a gestão ambiental, a pesquisa e desenvolvimento (P\&D). Além disso, há uma preocupação para que as empresas ofereçam treinamento e capacitação.

Propõe-se, assim, uma "educação para a nova indústria", mediante expansão e diversificação da oferta de educação básica, continuada e profissional ajustada às necessidades atuais e futuras da indústria; modernização, otimização e adequação da infraestrutura física de escolas e laboratórios; flexibilização no formato e nas metodologias de atendimento às demandas educacionais da indústria; capacitação de docentes, técnicos e gestores em tecnologias e gestão dos processos educacionais.

A chamada teoria do capital humano é o argumento utilizado pela Confederação Nacional da Indústria. O “capital humano nas organizações”, esboçado pela CNI (2007), é considerado, na sociedade do conhecimento, como o principal ativo das empresas, o qual “(...) é formado pelo conjunto de habilidades que as pessoas detêm, adquiridas por meio de processos educativos, treinamento ou da experiência (...)”. O foco da educação são as chamadas "competências básicas", que garantem ao trabalhador continuar aprendendo durante a vida. Para ter sucesso, contudo, a pessoa deve ser inserida no mercado de trabalho.

Constata-se a tentativa da indústria de aproveitar a oportunidade de qualificar o máximo de trabalhadores possível se faz alinhado com a chamada "janela de oportunidade demográfica" que se visualiza no Brasil nas próximas décadas. O elevado número de pessoas em idade ativa (PIA), nos próximos 30 anos, comparados aos beneficiários a serem protegidos dos riscos sociais, tais como crianças, jovens e idosos aposentados abre ao Brasil a possibilidade de, nos próximos anos, promover um grau de acumulação de "capital humano" inédito em sua história. Pela "teoria do capital humano", a força de trabalho tende a se tornar, com auxílio direto da educação, mais experiente, mais qualificada, mais competitiva e, portanto, apta a gerar maiores índices de produtividade.

A seguir o conceito de educação de Nussbaum (2013, pp. 396-397), todavia, ela (educação) é "a chave para todas as capacidades humanas". Logo, deveria ser concebida não meramente como fornecedora de habilidades técnicas úteis, mas como um meio de enriquecimento geral da pessoa, somente possibilitado por meio da informação, do pensamento crítico e da imaginação.

\section{Conclusão}

Do estudo realizado, pode-se, a título de indício, identificar o andamento de um 
"projeto nacional de educação para a indústria", possivelmente idealizado pelo setor empresarial, seja com intuito de superar um suposto conflito ideológico, seja com intuito de obter superávits mercadológicos, o que retiraria de uma ou mais gerações de estudantes muitas das suas alternativas de autodeterminação para escolher seu futuro, preparando-se de forma mais flexível e ampla, não tão direcionada a uma formação exclusiva ou preferencial para o trabalho, notadamente, em atividades subalternas ou acessórias, restando pouca ou nenhuma possibilidade de ascensão social, porque previamente dirigidos (ou "condenados") a estudar aquilo que lhes estiver disponível.

No tema em estudo, aceitar uma formação profissionalizante, voltada a ocupação de postos de trabalho em atividades de remuneração mediana ou baixa, significa aceitar uma vida sem perspectiva de acesso às funções ou profissões mais bem reconhecidas em termos remuneratórios ou de status social agregado, implodindo-lhes eventual projeto de vida bem sucedida, tão legítimo numa sociedade que prega o mérito.

A nova lei do Ensino Médio poderá empoderar novos modelos baseados no modal de terceirização e privatização, do ensino e do trabalho, mediante a redução da Base Comum Curricular, e, por conseguinte, da possibilidade de redução ou supressão de conteúdos antes ministrados aos estudantes, a fim de garantir uma formação mais rápida voltada ao mercado de trabalho.

As opções políticas buscam justificar a reforma no Ensino Médio sobre bases inovadoras, possivelmente, mediante a utilização de parcerias público-privadas, com o fim de ampliar a eficiência da gestão escolar e do trabalho docente e pela possibilidade de reforçar estratégias de ensino e aprendizagem, a fim de que os alunos possam elevar seus níveis de desenvolvimento educacional, especialmente, no tocante à língua portuguesa e a matemática, e, preparar o indivíduo para os desafios e adversidades da vida, tornando-o apto para o mercado de trabalho, entre outros. Isso colocado em prática implicará perda de autonomia das escolas e professores sobre o trabalho político-pedagógico, tornando a gestão pouco democrática.

Se hipoteticamente for confirmado o exercício do monitoramento dos personagens por critérios puramente de aferição produtiva, revelar-se-á uma perspectiva focada, exclusivamente, na eficiência e desenvolvimento econômico, mas frágil quanto ao cuidado com o fator humano, com vistas a atingir um pré-determinado resultado, qual seja, socorrer a falta de qualificação profissional. Tal técnica, se aplicada ao ensino e aprendizagem, demonstra a tentativa de simplificação da formação humana no processo de escolarização que se tenta impor por meio da nova Lei do Ensino Médio. O efeito de subjugar o profissional do ensino é a 
precarização do trabalho docente, já permeado por histórica desvalorização (salários baixos, falta de material de apoio pedagógico e infraestrutura adequada para o exercício da docência, tempo para o planejamento das ações pedagógicas, entre outros).

A nova lei do Ensino Médio, inicialmente, põe obstáculo ao acesso a uma formação intelectual integrada, na medida em que se revela ser o foco principal a formação para o mercado, a fim de proteger próprio aprendente e garantir o desenvolvimento econômico, sem que sejam reconhecidas as diversidades (de classe, étnico-racial, territorial, geracional, sexual, de identidade de gênero etc.), num contexto em que o protagonista é a pessoa em desenvolvimento e o seu direito fundamental ao pleno desenvolvimento e a nãoprofissionalização pura e simples nessa fase.

Para que a educação permita acesso aos bens primários, entre os quais a autoestima de inspiração rawsliana, deve-se garantir que o indivíduo possa se apropriar da cultura de sua sociedade e de toda a produção cultural humana, reforçando o valor de cada pessoa. Lembrando, que o efeito da primeira parte do "princípio da igualdade equitativa de oportunidades", impõe a toda a sociedade oportunizar iguais condições de educação para os seus membros.

Repisando-se, o papel da educação é possibilitar ao indivíduo uma ação refletida pelos princípios de justiça, somente possíveis de serem aceitos por pessoas racionais, livres e iguais, assim tornados por meio da educação. Portanto, o foco das políticas educacionais deve ser a extensão de oportunidades básicas para todos, cuja preocupação está nas capacidades ou habilidades, com especial atenção aos desfavorecidos e excluídos.

Inspirados no ideal nussbaumniano de "respeito igual pelas pessoas", demonstrado quando afirma que devem ser removidas as características estruturais do sistema mundial para o fim de promover as capacidades humanas para toda e qualquer pessoa, em vez de optar-se por tratar certos temas humanos relevantes como meramente instrumentais, deve-se buscar desenvolver as capacidades ou habilidades (capabilities), principalmente as operadas pelos sentidos, imaginação e pensamento.

Dessa maneira será possível ao indivíduo optar por uma ação refletida pelos princípios de justiça, que somente se fazem assimiláveis por pessoas racionais, livres e iguais, passíveis de serem consideradas e respeitadas como um fim em si, dentro de um contexto natural, e não como meios disponíveis aos interesses de terceiros ou pretensamente coletivos.

\section{Referências}


BARRAYCOA, Javier. Sobre el poder em la modernidade y la posmodernidad. Barcelona: Ensaios Sociales, 2002.

BRASIL. Lei n. 9.394, de 20 de dezembro de 1996. Disponível em: <http://legislacao.planalto.gov.br/legisla/legislacao.nsf/Viw_Identificacao/lei\%209.3941996?OpenDocument>, acesso em 06/07/2017.

Lei n. 13.415, de 16 de fevereiro 2017. Disponível em: <http://www.planalto.gov.br/ccivil_03/_ato2015-2018/2017/lei/L13415.htm>, acesso em 06/07/2017.

Medida Provisória n. 746, de 22 de setembro de 2016. Disponível em: <http://www.planalto.gov.br/ccivil_03/_ato2015-2018/2016/Mpv/mpv746.htm>, acesso em 06/07/2017.

. Ministério da Educação. Portaria n. 971, de 9 de outubro de 2009. Disponível em: <http://portal.mec.gov.br/docman/1634-port-971/file>, acesso em: 06/07/2017.

Supremo Tribunal Federal. Ação Direta de Inconstitucionalidade n. 5.599, Relator(a): Ministro Edson Fachin, julgado em 20/04/2017, publicado em Processo Eletrônico DJe-084, divulgado em 24/04/2017, publicado em 25/04/2017.

Confederação Nacional na Indústria (CNI). Educação para a nova indústria: uma ação para o desenvolvimento sustentável do Brasil. Brasília, DF: CNI, 2007.

FREEMAN, Samuel. Rawls. Taylor \& Francis e-Library, 2007.

MELLO, Alessandro de. A educação básica na proposta da Confederação Nacional da Indústria nos anos 2000. Educação e Pesquisa, São Paulo, v. 38, n. 1, pp. 29-45, 2012. Disponível em <http://www.redalyc.org/articulo.oa?id=29821428003> ISSN 1517-9702, acesso em 06/07/2017.

MONTEIRO, Agostinho Reis. O pão do direito à educação. Educação \& Sociedade. Revista de Ciência da Educação, Campinas, v. 24, n. 84, set. 2003.

MOREIRA, Orlando Rochadel. Políticas públicas e direito à educação. Belo Horizonte: Fórum, 2007.

MULINARI, Filício. Considerações Sobre A Pedagogia De Kant: Uma Educação Para A Autonomia. Revista Helius, ISSN 2357-8297, Ano 1, n. 1, Jul-Dez 2013, pp. 95-114. Disponível em <http://www.uvanet.br/helius/index.php/helius/article/view/36>, acesso em 07/07/2017.

NUSSBAUM, Martha. Fronteiras da Justiça: deficiência, nacionalidade, pertencimento à espécie. São Paulo: Martins Fontes, 2013.

. Women's Education: a Global Challenge. Journal of Women in Culture and Society. 2003, vol. 29 (Signs 29), no. 2, by The University of Chicago, pp. 325-355. Disponível em: 
<http://faculty.smcm.edu/jwschroeder/GlobalJustice2014/texts_files/Womens\%20Education A\%20Global\%20Challenge(2003).pdf>, acesso em 09/07/2017.

RAWLS, John. Uma Teoria da Justiça. Trad. Almiro Pisetta e Lenira M. R. Esteves. $1^{\text {a }}$ ed., São Paulo: Martins Fontes, 1997.

ROHLIING, Marcos. A educação e a educação moral em Uma Teoria de Justiça de Rawls. Fundamento Revista de Pesquisa em Filosofia, n. 4, jan/jun/2012. Disponível em http://www.periodicos.ufop.br/pp/index.php/fundamento/article/view/26, acesso em 06/07/2017.

RIBERIO, Monica. Como fica o ensino médio com a reforma - vem aí o Ensino Médio "líquido". Disponível em: <http://www.cedes.unicamp.br/noticias/668>, acesso em: 08/05/2017.

SALGADO, Joaquim Carlos. A ideia de justiça em Kant: seu fundamento na liberdade e na igualdade. $3^{\mathrm{a}}$ ed. Belo Horizonte: Del Rey, 2012.

SIMÕES, Willian. Nota técnica a lei n. 13.415, de 16 de fevereiro de 2017: elementos para debater a reforma do ensino médio e possíveis desdobramentos possíveis. Disponível em $<$ https://cageouffs.files.wordpress.com/2017/04/nota-pc3bablica_-a-contra-reforma-doensino-mc3a9dio_willian-simc3b5es_24032017.pdf>, acesso em 01/05/2017. 